\title{
Aircraft Scheduled Airframe Maintenance and Downtime Integrated Cost Model
}

\author{
Remzi Saltoğlu, Nazmia Humaira, and Gökhan İnalhan \\ Department of Aeronautical Engineering, Faculty of Aeronautics and Astronautics, ITU, Maslak Campus, Maslak, \\ 34469 Istanbul, Turkey \\ Correspondence should be addressed to Nazmia Humaira; humaira@itu.edu.tr
}

Received 30 October 2015; Revised 21 January 2016; Accepted 24 January 2016

Academic Editor: Shey-Huei Sheu

Copyright (C) 2016 Remzi Saltoğlu et al. This is an open access article distributed under the Creative Commons Attribution License, which permits unrestricted use, distribution, and reproduction in any medium, provided the original work is properly cited.

\begin{abstract}
Aviation industry has grown rapidly since the first scheduled commercial aviation started one hundred years ago. There is a fast growth in the number of passengers, routes, and frequencies, with high revenues and low margins, which make this industry one of the most challenging businesses in the world. Every operator aims to undertake the minimum operating cost and gain profit as much as possible. One of the significant elements of operator's operating cost is the maintenance cost. During maintenance scheduling, operator calculates the maintenance cost that it needs to budget. Previous works show that this calculation includes only costs that are directly related to the maintenance process such as cost of labor, material, and equipment. In some cases, overhead cost is also included. Some of previous works also discuss the existence of another cost throughout aircraft downtime, which is defined as cost of revenue loss. Nevertheless, there is not any standard model that shows how to define and calculate downtime cost. For that reason, the purpose of this paper is to introduce a new model and analysis technique that can be used to calculate aircraft downtime cost due to maintenance.
\end{abstract}

\section{Aircraft Maintenance Program}

1.1. Introduction. All machines, even the simplest ones, require maintenance after some defined periods of operation. Aircraft, which consists of different systems and structures, also has specific maintenance tasks that need to be performed to support its operation. As Gupta et al. [1] stated, the main objective of aircraft maintenance program is to deliver aircraft that is safe, airworthy, and punctual. Bazargan [2] also asserted that the objective of maintenance to yield safe and airworthy aircraft makes it the foundation of successful aircraft management. Hurst [3] stated that attaining the highest availability is the main objective of aircraft maintenance programs. Therefore, it is clear that maintenance programs have a very important role in the aviation industry. Maintenance programs help operators to reach important objectives such as safety, airworthiness, and high availability. Authorities require the operators to maintain their aircraft because it deals with the safety of many people. Furthermore, proper maintenance yields high aircraft punctuality, longer operating hours, and thus higher revenue for aircraft operators.
Aircraft maintenance programs can be performed either by the aircraft operator or by the Maintenance, Repair, and Overhaul (MRO) organizations. In both cases, they need to follow the specific procedures released by the aircraft, engine, and component manufacturers. Kinnison as cited in Eurocontrol [4] stated that Maintenance Planning Document (MPD) of Airbus or Maintenance Planning Data (MPD) of Boeing are examples of documents that are released by aircraft manufacturers for maintenance program preparation. Eurocontrol described that these documents contain usually what, how, and when the minimum mandatory maintenance tasks need to be performed. Using these documents, operators and MRO organizations can plan the maintenance programs accordingly.

Due to the fact that aircraft systems and structures require maintenance in different periods, the maintenance program is divided into categories according to their defined intervals. Following [4] Aircraft maintenance tasks are classified with increasing complexity (from simple to difficult) into line/transit, A, B, C, and D maintenance as shown in Table 1.

Eurocontrol [4] described that even though current maintenance programs are planned according to the 
TABLE 1: Typical maintenance checks, adapted from Eurocontrol [4].

\begin{tabular}{llll}
\hline Check & Location & Description & Duration \\
\hline Line & At gate & $\begin{array}{l}\text { Daily (before the first flight or when in transit). Visual } \\
\text { inspection; fluid levels; tires and brakes; emergency equipment }\end{array}$ & $\sim 1$ hour \\
\hline A & At gate & Routine light maintenance; engine inspection & $\sim 10$ hours \\
\hline B & At gate & $\begin{array}{l}\text { Similar to A check but with different tasks (may occur between } \\
\text { consecutive A checks) }\end{array}$ & $\sim 10$ hours to $\sim 1$ day \\
\hline C & Hangar & $\begin{array}{l}\text { Structural inspection of airframe, opening access panels; routine } \\
\text { and nonroutine maintenance; run-in tests }\end{array}$ & $\sim 3$ days to $\sim 1$ week \\
\hline D & Hangar & $\begin{array}{l}\text { Major structural inspection of the airframe after paint removal; } \\
\text { engines, landing gear, and flaps removed; instruments, } \\
\text { electronic and electrical equipment removed; interior fittings } \\
\text { removed; hydraulic and pneumatic components removed }\end{array}$ & $\sim 1$ month \\
\hline
\end{tabular}

TABLE 2: Typical maintenance check intervals for different aircraft types, adapted from Eurocontrol [4]. Multiple sources, including Aircraft Technology Engineering \& Maintenance, Aircraft Commerce and Boeing AERO.

\begin{tabular}{lcccc}
\hline Aircraft & A check & B check & C check & D check \\
\hline B737-300 & $275 \mathrm{FH}$ & $825 \mathrm{FH}$ & $18 \mathrm{MO}$ & $48 \mathrm{MO}$ \\
B737-400 & $275 \mathrm{FH}$ & $825 \mathrm{FH}$ & $18 \mathrm{MO}$ & $48 \mathrm{MO}$ \\
B737-500 & $275 \mathrm{FH}$ & $825 \mathrm{FH}$ & $18 \mathrm{MO}$ & $48 \mathrm{MO}$ \\
B737-800 & $500 \mathrm{FH}$ & $\mathrm{n} / \mathrm{a}$ & $4000-6000 \mathrm{FH}$ & $74 \mathrm{MO}$ \\
B757-200 & $500-600 \mathrm{FH}$ & $\mathrm{n} / \mathrm{a}$ & $18 \mathrm{MO} / 6000 \mathrm{FH} / 3000 \mathrm{FC}$ & $72 \mathrm{MO}$ \\
B767-300ER & $600 \mathrm{FH}$ & $\mathrm{n} / \mathrm{a}$ & $18 \mathrm{MO} / 6000 \mathrm{FH}$ & $72 \mathrm{MO}$ \\
B747-400 & $600 \mathrm{FH}$ & $\mathrm{n} / \mathrm{a}$ & $18 \mathrm{MO} / 7500 \mathrm{FH}$ & $72 \mathrm{MO}$ \\
A319 & $600 \mathrm{FH}$ & $\mathrm{n} / \mathrm{a}$ & $18-20 \mathrm{MO} / 6000 \mathrm{FH} / 3000 \mathrm{FC}$ & $72 \mathrm{MO}$ \\
A320 & $600 \mathrm{FH}$ & $\mathrm{n} / \mathrm{a}$ & $18-20 \mathrm{MO} / 6000 \mathrm{FH} / 3000 \mathrm{FC}$ & $72 \mathrm{MO}$ \\
A321 & $600 \mathrm{FH}$ & $\mathrm{n} / \mathrm{a}$ & $18-20 \mathrm{MO} / 6000 \mathrm{FH} / 3000 \mathrm{FC}$ & $96 \mathrm{MO}$ \\
ATR42-300 & $300-500 \mathrm{FH}$ & $\mathrm{n} / \mathrm{a}$ & $3000-4000 \mathrm{FH}$ & $96 \mathrm{MO}$ \\
ATR72-200 & $300-500 \mathrm{FH}$ & $\mathrm{n} / \mathrm{a}$ & $3000-4000 \mathrm{FH}$ & \\
\hline
\end{tabular}

Maintenance Steering Group (MSG) 3-task oriented principle, the letter check classification is still preferred in the aviation industry. However, in practice, it stated that depending on MRO organizations and aircraft types, the mandatory tasks and labor numbers will vary.

1.2. Scheduled Airframe Maintenance Checks. Besides line maintenance, airframe maintenance tasks are categorized into letter checks, which are labeled as A, B, C, and D. As Sriram and Haghani [5] asserted, maintenance programs consist of a sequence of checks with increasing complexity. Clarke et al., as cited in [6], stated that FAA requires four significant types of maintenance checks, A check, B check, $\mathrm{C}$ check, and D check, which vary in the areas maintained, duration, and the rate of occurrence. On that account, letter check maintenances vary depending on the types of the tasks to be performed and the duration needed to complete the tasks. In addition to the duration and type of the task, the frequency or interval of these letter checks also varies. Eurocontrol [4] showed the typical intervals of letter maintenance checks of twelve aircrafts as given in Table 2 .

In view of the information provided in Table 2 , it can be seen that the rate of occurrence of $\mathrm{A}$ and $\mathrm{B}$ checks are determined by the number of flight hours $(\mathrm{FH})$, while the interval of $\mathrm{C}$ check depends on $\mathrm{FH}$, flight cycle (FC), and calendar months (MO). On the other hand, the interval of $\mathrm{D}$ check depends on MO. Hence, it can be concluded that FH, FC, and MO determine the period of the maintenance checks. Eurocontrol [4] described that between the three of them, the one that occurs first determines the need for maintenance of the aircraft. As examples, they stated that for an aircraft that is used for long-haul flights, the check will be mostly determined by flight hours, ignoring the flight cycles and calendar months, while for an aircraft that operates frequently for short haul flights, the flight cycles will mostly determine its maintenance checks. On the other hand, if the aircraft is not used frequently, the number of calendar months will determine its maintenance checks, ignoring its flight hours and flight cycles [4].

\section{Aircraft Maintenance Cost}

2.1. Maintenance Cost in Literature. IATA's MCTF FY2013 [8] presented that 48 airlines reported for direct maintenance cost of $\$ 13.1$ billion and 34 airlines reported maintenance overhead of $\$ 2.6$ billion. In their report, it is also asserted that per flight hour $(\mathrm{FH})$ the average maintenance cost is $\$ 1,167$ per flight cycle (FC) it is $\$ 3,021$ and per aircraft is $\$ 3.1$ million. In addition to IATA's MCTF FY13 data, Eurocontrol [4] also presented data on the subject of direct maintenance cost together with maintenance overhead cost as unit maintenance cost as shown in Table 3. 
TABLE 3: Maintenance costs (including burden) per block hour in 2008, all costs are Euros per block hour and include burden, adapted from Eurocontrol [4].

\begin{tabular}{lccc}
\hline \multirow{2}{*}{ Aircraft } & \multicolumn{3}{c}{ Unit maintenance costs } \\
& Low & Base & High \\
\hline B737-300 & 690 & 740 & 900 \\
B737-400 & 710 & 760 & 930 \\
B737-500 & 570 & 620 & 770 \\
B737-800 & 500 & 540 & 670 \\
B757-200 & 840 & 900 & 1090 \\
B767-300ER & 930 & 970 & 1280 \\
B747-400 & 1440 & 1500 & 1930 \\
A319 & 580 & 630 & 800 \\
A320 & 570 & 620 & 770 \\
A321 & 660 & 720 & 910 \\
ATR42-300 & 350 & 370 & 380 \\
ATR72-200 & 430 & 460 & 460 \\
\hline
\end{tabular}

The values displayed by Eurocontrol in Table 3 show direct maintenance costs per block hour for twelve different aircrafts. However, those values are already the mixture of line, base, component, and engine maintenance cost. Therefore, it is not possible to derive for example, the aircraft's base maintenance unit cost only. On the other hand, IATA [8] presents the evolution of direct maintenance cost of 26 airlines with different fleets of different aircraft types. IATA presented the maintenance cost per flight hour of different segment. Therefore it is possible to observe the evolution of line, base, engine, and component maintenance cost. However, the maintenance cost for a specific aircraft type is not stated.

2.2. Maintenance Cost Elements. Aircraft maintenance cost varies depending on many elements. Eurocontrol [4] stated that age is a very crucial element in determining maintenance cost for an aircraft and its engines. At the early age of the aircraft, its maintenance cost is predictable; however, as it gets older, its maintenance cost increases since aging systems and structures require extra maintenances. In addition to aircraft's age, Papakostas et al. [9] stated that elements that affect the maintenance cost are equipment and facility costs, supplies and logistics costs, labor cost, and overhead. Therefore, it is clear that each maintenance check has different cost depending on aircraft's age and the required equipment, material, and labor. For example, a $\mathrm{C}$ check has longer duration and more complex tasks than an $\mathrm{A}$ check and will require more equipment, materials, and labors/man-hours to complete all the tasks. Obviously, these requirements result in higher cost for performing $\mathrm{C}$ check, compared to A check.

Dupuy et al. [10] stated that direct maintenance cost, which is composed of cost of maintenance crews, materials, and parts repair and replacement, accounts for $11 \%$ of the total operating cost of an aircraft. Kumar et al. [11] stated that direct maintenance cost (CMT) consists of cost of maintenance resources, which is given by:

$$
\mathrm{CMT}=C_{s}+C_{m}+C_{p}+C_{\mathrm{te}}+C_{f}+C_{d},
$$

where $C_{s}$ is cost of spare parts, $C_{m}$ is cost of material, $C_{p}$ is cost of personnel, $C_{\mathrm{te}}$ is cost of tools and support equipment, $C_{f}$ is cost of facilities, and $C_{d}$ is cost of technical data.

\section{Scheduled Airframe Maintenance Cost Elements}

When aircraft operator outsources its base maintenance requirements to a third party $\mathrm{MRO}$ organization, the cost breaks down mainly into labor and material elements. They are labor rate (LBR), MPD tasks labor (MTL), engineering order labor (EOL), nonroutine labor (NRL), cosmetic items labor (CIL), MPD tasks material (MTM), engineering order material (EOM), nonroutine material (NRM), and cosmetic items material (CIM). Each element has a source from the maintenance program. But since a substantial portion of the elements are uncertain, the type and age of the aircraft and the point of time in the maintenance history affect the magnitude of both labor and material costs at each base maintenance event (check).

Labor rate (LBR) is the dollar value per each manhour that a maintenance organization charges for its services on the aircraft. This rate changes in accordance with cost base, for example, according to the geographical location of the maintenance facility. However, location is not the only factor of this rate change. Market conditions, special service requirements, and seasonal factors also affect the labor rate. Base maintenance service contracts incorporate this rate for a fixed price and also for nonroutine and additional services. It is common that labor rate may differ within an organization, through fixed price services and different skill sets.

MPD tasks labor (MTL) represents the labor requirement of maintenance program tasks. Since MTL defines routine works, the planners could determine this parameter in advance. This element will be the same for each aircraft going under the exact same scope of work in a base maintenance event. However, changes will appear amongst different maintenance service providers, which are explained by the term MRO efficiency factor (MEF).

$\mathrm{MRO}$ efficiency factor (MEF) is a factor, which represents the ratio of the average man-hour required by a MRO to complete a maintenance task and the man-hour for that task given in manufacturer's Maintenance Planning Document (MPD). For a MRO with high ranking in terms of delivery performance, the MEF value is expected to be low. Therefore, it is acceptable to see MRO organizations, with lower MEF value, have higher LBR. In other words, MRO organizations with lower LBR are supposed to have higher MEF, which increases all labor related cost elements. MEF is a value above 1 , where 1 can only be reached in ideal conditions. Personnel training and experience, tool and material availability, and hangar conditions are some factors that affect MEF. MEF value decreases as MRO has higher investment (in maintenance environment) and experiences on a specific task or aircraft type.

MPD tasks material (MTM) is another deterministic element. The routine works and associated material requirements are predefined for each task, which is grouped into a scheduled maintenance check per interval limitations. 
Therefore, MTL and MTM cost elements are not probabilistic. Two other deterministic elements are EOL (engineering order labor) and EOM (engineering order material). These are the labor amount and material cost arising from Engineering Order requirements. MTL, MTM, EOL, and EOM can be observed to increase on an aging aircraft. However, these parameters can still be determined during the checkplanning phase.

Nevertheless, not all the cost elements have deterministic character. Nonroutine related labor and material cost elements tend to change with type, age, and operation condition of aircraft. General assumptions could be made; however, the most accurate cost of these elements could only be calculated after the performance of the check.

Taking into account all the elements given above, the cost of a scheduled airframe maintenance check can be calculated by the following equation:

$$
\begin{aligned}
& \text { MTC } \\
& =\mathrm{LBR} \\
& \quad *(\mathrm{MEF} *(\mathrm{MTL}+\mathrm{EOL}+\mathrm{NFL} *(\mathrm{NRL}+\mathrm{CIL}))) \\
& \quad+\mathrm{MTM}+\mathrm{EOM}+\mathrm{NFM} *(\mathrm{NRM}+\mathrm{CIM}),
\end{aligned}
$$

where all the material-related variables such as MTM, EOM, NRM (nonroutine material), and CIM (cosmetic items material) are already given in dollars. Furthermore, to identify the probabilistic character of nonroutine related labor and material costs, the terms NFL, which corresponds to nonroutine labor factor, and NFM, which corresponds to nonroutine material factor, are used. These factors are expected to increase on old aircrafts and should also differ for each aircraft and check type.

Turn-around time (TAT), which does not appear in the equation above, is the most crucial element. TAT does not contribute to direct maintenance cost but it contributes to the downtime cost of the aircraft. Assuming that the sum of the elapsed time of critical maintenance tasks is lower than TAT, then TAT can be calculated by the following equation:

$$
\mathrm{TAT}=\mathrm{MEF} * \frac{\mathrm{MTL}+\mathrm{EOL}+\mathrm{NFL} *(\mathrm{NRL}+\mathrm{CIL})}{\mathrm{MLC}},
$$

where MRO labor capacity (MLC) is the maintenance facility's daily labor production capacity, which depends on the number of the assigned technicians to the aircraft and the daily working hours (shift pattern).

In some cases, when there are substantial nonroutine works, TAT becomes the sum of the total critical tasks (routine and nonroutine) of the scheduled maintenance check. In addition, logistic factors such as long durations of material procurement of nonroutine tasks could also increase TAT. In this study, TAT of a scheduled maintenance check will be incorporated in the maintenance cost with the term downtime (DT):

$$
\mathrm{TAT}=\mathrm{DT} .
$$

\section{Downtime in Literature}

Dupuy et al. [10] asserted that maintenance cost is not the only cost that aircraft operator has to support at the time maintenance is performed. They noted that operator is also subject to indirect maintenance cost. One element of indirect maintenance cost is covered in $[4,8]$ as overhead cost. Overhead cost does not contribute directly to the maintenance program but it does contribute to the overall cost that the operator undertakes during maintenance. In addition to overhead cost, there is another element of indirect maintenance cost that appears due to aircraft downtime. Hurst [3] asserted that it is important to control the rate of aircraft downing event since it makes an aircraft unavailable to fly. The cost element related to downtime is described as downtime cost. It appears to be due to the fact that aircraft stays on the ground and ceases to operate throughout maintenance.

Kumar et al. [11] asserted that downtime should be considered only when the system is expected to be in operation. They discussed that scheduled and preventive maintenance are usually performed when the system is not required to be operational. Therefore, they noted that this period does not have any impact on the revenue generating capacity of the aircraft. Following [11], the cost of lost revenue due to downtime is expressed as follows:

$$
\mathrm{CLR}=(\mathrm{DMT}+\mathrm{DST}) * \mathrm{IHR}=\mathrm{DT} * \mathrm{IHR},
$$

where CLR is cost of loss of revenue, DMT is the duration of maintenance task, DST is the duration of support task, IHR is the income hourly rate, and DT is the total downtime.

On the other hand, Saranga [12] stated that whenever a system stops to operate, whether it is scheduled or unscheduled, the cost of lost revenue (CLR) is an unexceptional and an unavoidable cost. In his research, he described that downtime cost is a very complex component, which relies on the season type, business environment, unscheduled or scheduled type of downtime, and some other factors. Both downtime cost caused by scheduled and unscheduled maintenance are costly. Furthermore, Saranga discussed that an unscheduled downtime for a commercial airline during high season will require some auxiliary actions that increase downtime cost, which is classified as cost of compensation. Following [12], the cost of downtime due to scheduled maintenance is calculated by the following equation:

$$
\mathrm{CDTp}=\mathrm{CLR} * \mathrm{DT},
$$

where CDTp is cost of downtime for planned maintenance, CLR is cost of lost revenue, and DT is downtime in hours.

Subsequently, cost of downtime due to unscheduled maintenance is expressed as follows [12]:

$$
\mathrm{CDTu}=\mathrm{CDTp}+\mathrm{ICD},
$$

where CDTu is cost of downtime for unscheduled maintenance and ICD is indirect cost of downtime, which is given by [12]:

$$
\mathrm{ICD}=\mathrm{CC}+\mathrm{CGW}+\mathrm{CLD},
$$


where CC is cost of compensation, CGW is cost of goodwill, and CLD is cost of logistic delay.

Comparing the formulation given by [11, 12], it can be seen that the formulation set by [11] takes into account downtime cost as a cost that occurs only when the system is expected to be operational. This cost is defined as cost of lost revenue and does not include the potential auxiliary cost. However, [12] proposed downtime cost formulations both for scheduled and for unscheduled maintenance. For unscheduled maintenance, in addition to the cost of revenue loss, there are auxiliary costs added to downtime cost. Another model is proposed by Bazargan [2], who presented a mathematical model for aircraft dispatching strategy in order to have minimum total maintenance cost and an increase in aircraft availability for Cessna 172 aircrafts used for flight training. Nevertheless, since these aircrafts are not used commercially, only direct maintenance cost was taken into account in the analysis.

Taking into account all the information given, this paper agrees with [12] on the subject of downtime cost, which appears both during scheduled and unscheduled maintenance. By calculating downtime cost for scheduled maintenance, maintenance cost optimization can be achieved. However, in any of previous studies $[8,11,12]$ the seasonal characteristic of scheduled downtime cost has not been taken into account. As our main argument, we introduce downtime cost with its monetary value and add its seasonal character, which is still a virtual parameter. In this sense, an experiment based model validation is not possible. However, the rest of the model, which works together with the downtime cost, could be checked with real life cases, through the review of MRO cost and airline spending in particular scheduled maintenance events.

\section{Downtime as a Cost}

As direct maintenance cost is not cheap, so is downtime cost. Therefore, before preparing a maintenance schedule, operators need to calculate direct and indirect maintenance cost together with downtime cost in order to make a decision with the lowest possible total maintenance cost. Due to the seasonality of commercial aviation business, there may exist a certain period where downtime cost is higher than direct maintenance cost. On the other hand, another period may have lower downtime cost compared to direct maintenance cost.

Before developing a model of downtime cost that includes seasonal characteristics, a set of operation and revenue data of a scheduled operator (operator $\mathrm{ABC}$ ) and a MRO organization (MRO XYZ), both based in Istanbul, Turkey, are analyzed. Given the nature of business, neither MROs nor airlines allow disclosure of such financially sensitive data in their relevant competitive markets. For this confidentiality reason, normalization is utilized. In the operation of the scheduled operator $\mathrm{ABC}$, two types of seasons are taken into account. They are winter season, which lasts from November to March, and summer season, which lasts from April to October. The average monthly revenue generated by each aircraft (B737-800) is plotted in Figure 1. As expected, the

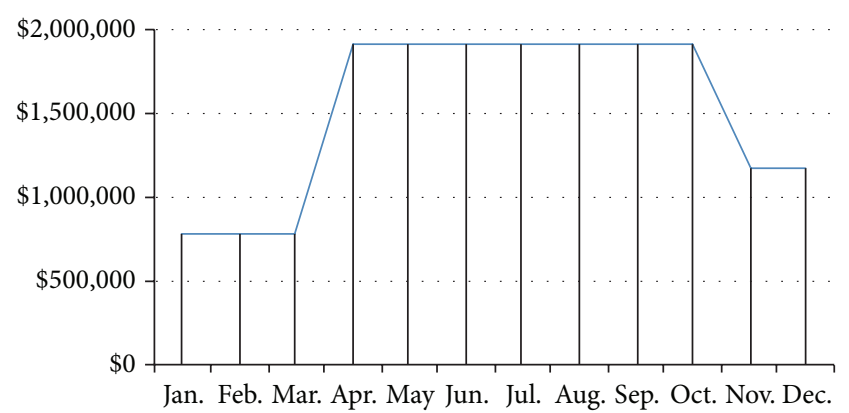

FIgURE 1: Scheduled operator $\mathrm{ABC}$ revenue per $\mathrm{A} / \mathrm{C}$.

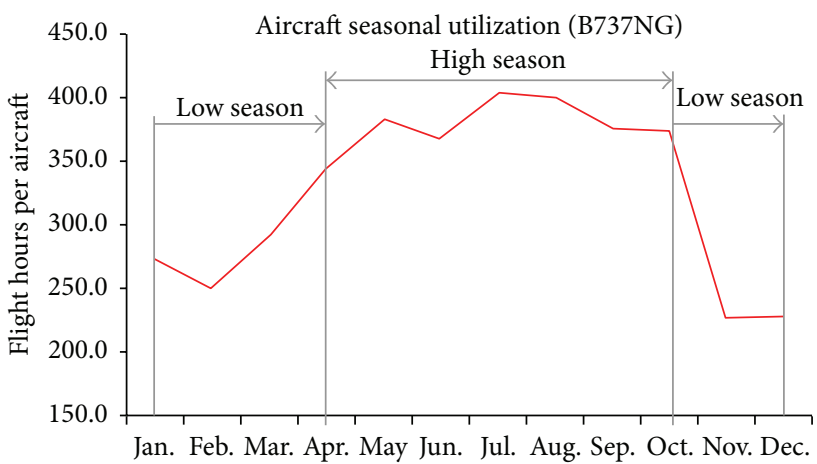

FIGURE 2: Aircraft seasonal demand, adapted from Muchiri and Smit [7].

resulting plot shows similar seasonal characteristics with the aircraft seasonal demand plot given by Muchiri and Smit [7] as shown in Figure 2. In Figure 2, aircraft demand is at peak between April and October; therefore this interval is classified as high season. On the other hand, between November and March, the demand is low; consequently the interval is classified as low season. This aircraft seasonal demand plot explains why the revenue of operator $A B C$ is high throughout summer and lower throughout winter.

The direct maintenance cost that appears to the operator during maintenance is a cost, which is offered by the MRO organization as maintenance service provider. As the revenue of scheduled operator varies seasonally, the revenue of MRO organization is also expected to fluctuate according to the season or the time of the year. In order to observe this effect, the average monthly revenue from base maintenance of MRO $\mathrm{XYZ}$ is analyzed and the result is plotted as shown in Figure 3.

In view of the information given in Figures 1 and 3, it can be seen that the plot of operator's revenue in Figure 1 is more or less the mirror image of the plot of MRO organization's revenue in Figure 3. Throughout high season, the revenue of operator is high, while the revenue of MRO organization is low. Figure 2 explains this trend in which during that period, the demand of aircraft is high and therefore instead of having maintenance performed on their aircrafts, operators prefer to fly them to meet the demand. For that reason, the demand for maintenance service is low. On the other hand, throughout low season, the demand of aircraft is low; thus as a consequence, the revenue of operator is also low. 


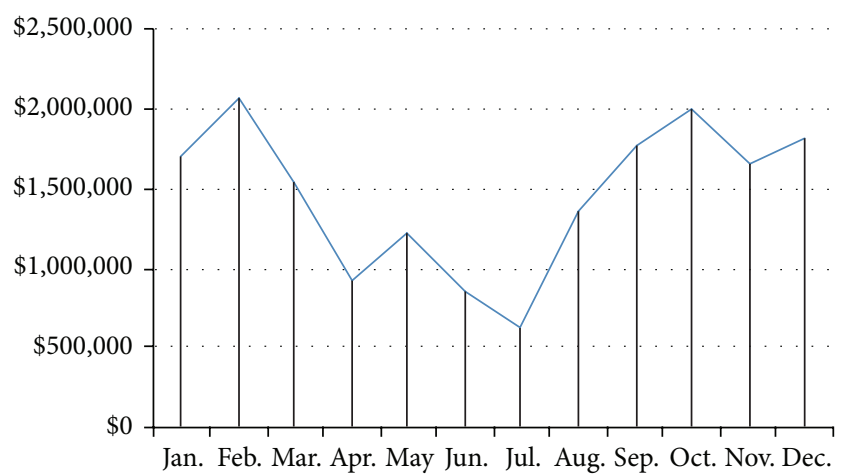

FIGURE 3: MRO XYZ revenue from base maintenance in 2014.

On that account, operators prefer to perform the required maintenance during this period so that their aircraft will be at the required reliability level before high season arrives. As a result, the demand for maintenance is high and that reflects on the increase in the revenue of MRO organization.

From these figures, operators can actually see that, during high season, there is a possibility of having better commercial terms of agreement, including maintenance price and rates from MRO organization, seeing that the demand of maintenance at that time is low. However, operators need to calculate the downtime cost and analyze its variation for different time periods. As it has been mentioned before, there may exist a period where downtime cost is lower than direct maintenance cost. For each period, operator may sum downtime cost with the offered maintenance cost to have the total maintenance cost.

\section{Downtime Cost Modeling for Scheduled Maintenance}

6.1. Downtime Cost Flow Chart. When signing maintenance contracts with maintenance service providers, aircraft operators use various methods to quantify their downtime cost. One of these methods refers to the cost of lease as the daily cost that appears once lease agreement is taken into account. Another method is based on subcharter cost that would rise when the flights of the grounded aircraft will be outsourced to a charter airline with a subcharter agreement. In another method, the loss of opportunity is also examined. In some previous work [11, 12] it is called cost of revenue loss. In this case, the potential revenue could be estimated on a seasonal basis, with two basic models: charter/ACMI and scheduled operators. To be able to calculate downtime cost properly before preparing a maintenance plan, the existence of a standard model for downtime cost calculation is thereby required. Such calculation should be precise, be in dollar values, and reflect the seasonal effects, in order to be useful during the decision making of maintenance schedule.

The flow chart given in Figure 4 shows the steps required to calculate aircraft downtime cost. At the beginning, operator needs to determine the period where maintenance is scheduled. Then, operator needs to see whether during that period there are flights assigned to the aircraft (aircraft in

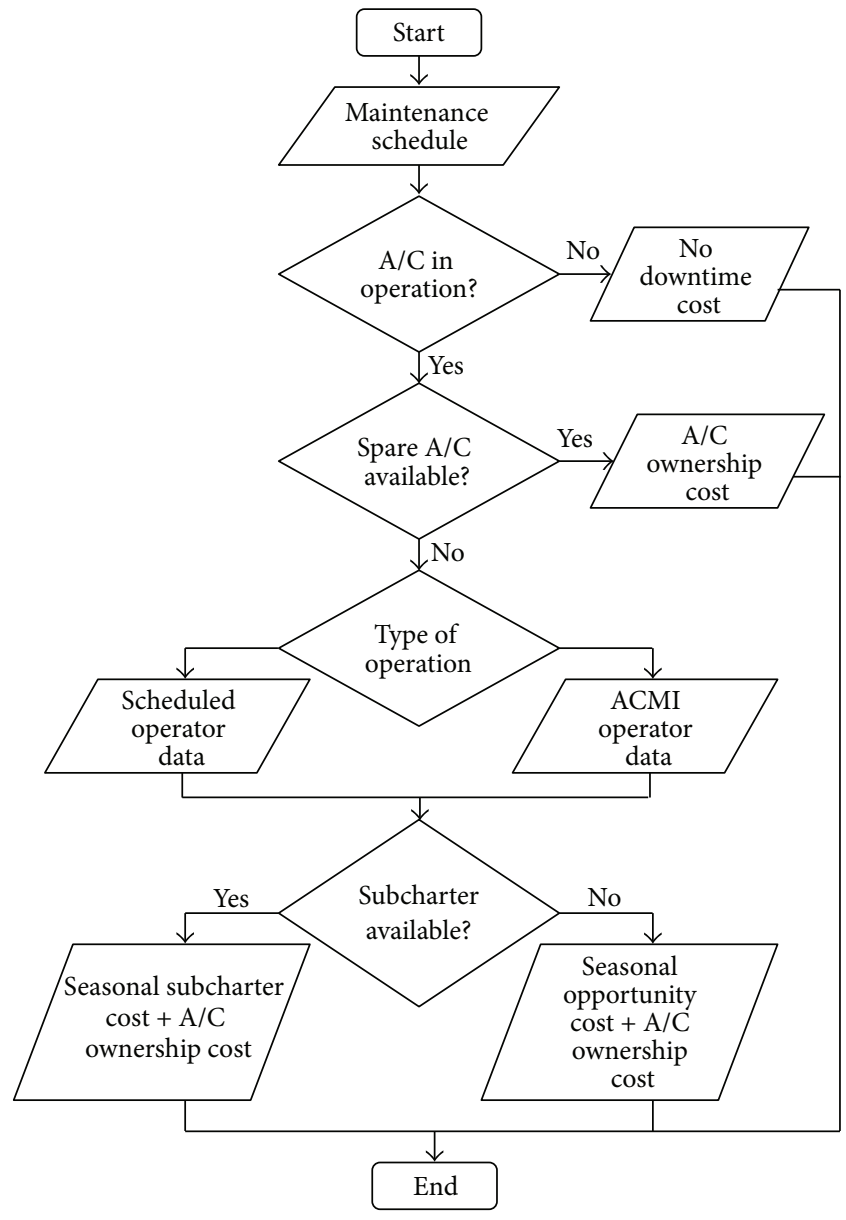

FIgURE 4: Downtime cost's flow chart.

operation) or not. If during that period the aircraft is not in operation, then there is no downtime cost. But if the aircraft is in operation, then operator needs to see if any spare aircraft is available or not. In the case where spare aircraft is available, downtime cost consists of aircraft ownership cost only. Otherwise, the type of operation of the operator will be analyzed, whether it is a scheduled operator or an ACMI (Aircraft, Crew, Maintenance and Insurance) operator. Subsequently, the operator needs to see the possibility of subchartering another aircraft throughout maintenance. Given that subchartering is chosen, then downtime cost will consist of subcharter cost and aircraft ownership cost. However, in the event that subchartering is not accepted as a solution, downtime cost will consist of opportunity cost and aircraft ownership cost. The type of operation, scheduled or ACMI, will determine the value of opportunity cost.

6.2. Aircraft Ownership Cost. Whether aircraft flies or not, its monthly lease cost is inevitable. Aircraft lease cost varies depending on aircraft's type, age, and configuration [13]. It will also vary depending on the market condition, the lessee fleet size, and aircraft's financial status. For the same aircraft type, the lease rate is cheaper for older aircraft. However, it is clear that older aircrafts have higher maintenance cost 
compared to the newer ones. They are more prone to supplementary maintenance tasks since their airframe and components are older.

The aircraft's total lease cost during downtime (ALC) can be calculated by the following equation:

$$
\mathrm{ALC}=\mathrm{DLC} * \mathrm{DT} .
$$

Recall that DT corresponds to downtime number of days and DLC corresponds to daily lease cost, which is given by

$$
\mathrm{DLC}=\frac{\mathrm{MLR}}{\mathrm{NDM}}
$$

In the case where operator does not lease the aircraft but owns it, instead of lease cost, ownership cost will be applied. Heiter [14] from Boeing showed one example of ownership cost calculation per trip for 787 Dreamliner with 13.5 block hours of available daily utilization and 12.44 block hours of daily designed mission. Nevertheless, there is no exact information on how the cost per month for 787 Dreamliner is obtained. But it is assumed that the monthly ownership cost is obtained from the multiplication of the aircraft's current market value (CMV) with $1.009 \%$. On that account, the ownership cost during downtime (OWC) can be calculated by the following equation:

$$
\mathrm{OWC}=\mathrm{OWD} * \mathrm{DT},
$$

where OWD is given by

$$
\mathrm{OWD}=\frac{\mathrm{MOC}}{\mathrm{NDM}}=\frac{\mathrm{CMV} * 0.01009}{\mathrm{NDM}} .
$$

6.3. Subcharter Cost. In case aircraft availability does not meet the regular demand, both scheduled and ACMI operators may subcharter aircraft from another operator to fulfill the demand. One of the reasons why aircraft is not available to meet the demand is due to maintenance. There exist two possible ways of sustaining the operations, while the aircraft is on the ground. First, operators may modify the schedule of the remaining aircraft and put the schedule of the aircraft under maintenance to another aircraft. Operators may not need to modify the existing schedule if they do have a spare aircraft on ground. However, most operators keep spare aircraft only in very rare and specific operation contracts and such application is not commonly seen in the industry. Second, if a spare aircraft is not available and schedule modification is also not possible, in order to keep fulfilling the demand, operators may subcharter aircraft from another operator. Within this context, when an airline has to subcharter a portion of its operations to another airline, the cost which occurred due to this service could be defined as another element of downtime cost.

It will be noted that scheduled operators should provide service according to their predefined schedules. It is generally not an option to cancel any given flight except during bad weather conditions. Therefore, it becomes a must to use either subcharter services or a spare aircraft to cover the unscheduled unavailability, which is a direct cost of downtime.
Aircraft subcharter service providers are usually ACMI operators. ACMI's subcharter cost includes the aircraft lease, crew, maintenance, and insurance costs. The costs that are not included are the operating costs such as fuel, navigation, ground handling, and taxes.

In the same way that the aircraft downtime cost is, subcharter cost is also complex. It depends on the business environment, market, and season condition. Figure 2 may give an insight into the variation of subcharter price according to the season. When the traffic or demand for aircraft is high, subcharter service provider may charge high subcharter price. On the other hand, when the demand for aircraft is low, it may charge lower subcharter price. Subcharter prices also vary according to the operation location, operational requirements, aircraft capacity and configuration, sectors, monthly confirmed block hours, and duration of the contract.

Subcharter cost during downtime (SAC) can be calculated by the following equation:

$$
\mathrm{SAC}=\mathrm{SAD} * \mathrm{DT},
$$

where SAD is given by

$$
\mathrm{SAD}=\frac{\mathrm{MSR}}{\mathrm{NDM}}=\frac{\mathrm{BH} * \mathrm{SCR}}{\mathrm{NDM}} .
$$

Recall that BH and SCR correspond to monthly block hour and subcharter rate, respectively.

6.4. Opportunity Cost. Another element of downtime cost is the cost of revenue loss as mentioned in [11, 12]. This could also be defined as the cost of opportunity loss as airplane being grounded instead of flying [10]. Such element is applicable for both scheduled and ACMI operators. The basic salaries of the crew are constant and independent from the flight schedule. Direct costs such as fuel and navigation charges and the flight compensations and hotel costs will arise only when the flight takes place. Therefore, it is reasonable to choose operator's average profit, which is the profit that operator would be able to generate if the aircraft does not cease to operate, as one element of downtime cost.

The opportunity cost per flight (OPF) can be calculated by the following equation:

$$
\mathrm{OPF}=\mathrm{ACP} * \mathrm{LF} * \mathrm{NPP} .
$$

Recall that ACP, LF, and NPP correspond to aircraft capacity, load factor, and net profit per passenger, respectively.

In the case where operators do not have their own data of net profit per passenger per flight, they can use the value proposed by IATA [15]. They stated that, in 2013, airlines obtained a net profit of $\$ 3.38$ per passenger, while in 2014 airlines received $\$ 6.02$ per passenger. IATA predicted that, in 2015 , airlines will earn $\$ 7.08$ net profit per passenger. Therefore, the opportunity cost per flight can be also calculated by the following equation:

$$
\mathrm{OPF}=\mathrm{ACP} * \mathrm{LF} * \$ 7.08,
$$

where the term NPP in this case is replaced by IATA's net profit per passenger value in 2015 . 
The opportunity cost calculation will vary according to the type of operation of the operators. In this study, two types of operators are considered. They are scheduled operators and ACMI or charter operators. Scheduled operators are operators with previously defined flight schedules such as legacy carriers and low cost carriers. The business model of scheduled airlines originates in regular frequency and published schedules and price [16]. An airline, which is providing scheduled passenger service, is expected to generate more revenue per flight hour when compared to a charter service provider. The current charging mechanisms allow airlines to apply varying fee per seat on scheduled services, thus allowing them to adapt to market conditions in the competitive market. In the context of maintenance and downtime costs, summer seasons are more valuable in the sense of flying.

On the other hand, ACMI operators provide aircraft charter services both for commercial and private purposes. Kim and Barnhart [17] asserted that the market type that is served by charter operators for a given origin and destination has exact demand, which varies only by day in a week. In view of this information, it is clear that the type of ACMI operator that is meant in this study is the operator that provides service for commercial purposes, for example, for a travel group. This is comparable with the service provided by scheduled operators.

Since their operation type is different, it is obvious that their profit calculation is also different. A scheduled service provider is expected to generate a range of profit between $\$ 10.000$ and $\$ 20.000$ during low and high seasons, respectively, while a typical ACMI operator's profit for a narrow body airplane could be estimated as $\$ 5000$ during the low season and $\$ 10.000$ during the high season. These profit values depend on several factors such as geographical region, aircraft configuration, and service level.

For a scheduled operator with fixed amount of flight frequency, the total opportunity cost (OPCs) can be calculated by summing the opportunity cost of all the scheduled flights that normally exist during the period where maintenance is planned. The equation is given by

$$
\mathrm{OPCs}=\sum_{s=1}^{S} \mathrm{OPF} \text {, }
$$

where OPFs corresponds to the opportunity cost per flight of a scheduled flight $s$ and $S$ is the number of scheduled flights.

For ACMI operator with no fixed schedule, the total opportunity cost (OPCc) can be calculated by summing the opportunity cost of all possible charter flights that usually exist during the period where maintenance is planned. The equation is given by

$$
\mathrm{OPCc}=\sum_{c=1}^{\mathrm{C}} \mathrm{OPF} \mathrm{c}
$$

where OPFc corresponds to the opportunity cost per flight of a possible charter flight $c$ and $C$ is the number of charter flights.
6.5. Downtime Cost Model. As the profit level of an airline increases, either by the operation type or by seasonal effect, the overall impact of downtime increases. In this study, two types of downtime cost are proposed. The first one is downtime cost with subcharter option (DTCs) and the second one is downtime cost with no subcharter option (DTCn). It is important to note that opportunity cost will appear only if operator decides not to take subcharter option to substitute the aircraft that is down for maintenance. In the case where operator chooses to subcharter an aircraft to keep the operation, instead of opportunity cost, subcharter cost will appear. On that account, downtime cost of an operator with subchartering an aircraft as an option is given by

$$
\text { DTCs }=\mathrm{AOC}+\mathrm{SAC} \text {, }
$$

where AOC corresponds to aircraft ownership cost, which represents either aircraft lease cost (ALC) or ownership cost (OWC).

Subsequently, downtime cost of an operator with no subcharter option is given by

$$
\mathrm{DTCn}=\mathrm{AOC}+\mathrm{OPC}
$$

Recall that OPC can be either OPCs or OPCc, which correspond to the total opportunity cost of scheduled and charter operator, respectively.

Taking into account the seasonal characteristics of each element, aircraft ownership cost (AOC) is assumed to be constant. However, subcharter (SAC) and opportunity cost (OPC) can be higher in the course of high season than in the course of low season as shown in Figures 1 and 2. This is crucial, where in addition to the duration of downtime, the accuracy of the downtime period becomes significantly important. In the region where Turkey is located, the high season for aircraft passenger traffic takes place throughout summer. On the contrary, there is relatively less demand for flights during winter. There are exceptions to the high and low seasons, as there are temporary peaks of demands during religious holiday periods of Ramadan, Christmas, and Haj. Since the dates of these religious holidays vary every year, downtime cost forecasting of charter/ACMI operator becomes very challenging. On the other hand, scheduled operators can perform better predictions on their downtime cost since their flight schedules are already established in advance.

Finally, the total maintenance cost with subcharter option is given by the following equation:

$$
\text { TMCs }=\text { MTC + DTCs. }
$$

Following that, the total maintenance cost with no subcharter option can be calculated by

$$
\mathrm{TMCn}=\mathrm{MTC}+\mathrm{DTCn}
$$

Recall that DTCn corresponds to downtime cost of an operator with no subcharter option. 


\section{Case Study}

This case study examines the total maintenance cost, which includes maintenance cost (MTC) and downtime cost (DTC), of an A320 aircraft during one light $\mathrm{C}$ check, for example, $\mathrm{C} 1$, in the first base check cycle [18]. The case study uses real data coming from a MRO, an airline and IATA [15]. A scheduled operator operates the aircraft, which seats 180 passengers in a high-density layout [19]. Belobaba et al. [20] discussed the daily utilization block hour of an A320 aircraft, which varies from 9.6 block hour $(\mathrm{BH})$ to 12.9 block hour in seven different US airlines. In this case, the average of 11 block hour daily utilization is chosen, which approximately corresponds to five scheduled flights each day. The elements of MTC and downtime (DT), such as CIL, EOL, and MTL, are obtained by adjusting properly the values existing in Aircraft Commerce [18]. MTL corresponds to the average of Routine $\mathrm{MH}$ (man-hour) divided by two; CIL corresponds to half of the addition of Other $\mathrm{MH}$ with the average of Interior $\mathrm{MH}$ and average of Strip and repaint. EOL corresponds to the average of ADs, SBs, and EOs $\mathrm{MH}$ divided by two. Division by two is done assuming that the MEF considered in [18] is two. For example, in [18] for light C checks, the Routine $\mathrm{MH}$ ranges from 1250 to 2200 . In our case study, its average, which is equal to 1725 , is divided by two so that $862.5 \mathrm{MH}$ is obtained as MTL. Later, in the calculation of DT and MTC, the MTL, CIL, and EOL parameters will be multiplied by the defined MEF value. As an example, in Table 4, the chosen MEF value is 2. The other parameters, such as MTM, CIM, and EOM, are obtained by multiplying MTL, CIL, and EOL by 50 dollars, respectively. The NFL and NFM percentages are $100 \%$, taking into account the worst case where all nonroutine tasks must be performed. The labor rate (LBR) values of $\$ 50$ in winter and $\$ 40$ in summer are obtained from real LBR values of MRO XYZ. The MRO labor capacity (MLC) of $160 \mathrm{MH}$ /day in winter and $200 \mathrm{MH}$ /day in summer is also procured from MRO XYZ. The seasonal load factor (LF) and monthly block hour $(\mathrm{BH})$ values are obtained by taking the average values throughout a year of scheduled operator ABC. Besides that, scheduled operator ABC also provided information regarding the seasonal subcharter rate per block hour (SCR). The monthly lease rate (MLR) is taken from Aircraft Value News [13]. The net profit per passenger (NPP) is the airline profit value per passenger in 2015 proposed by IATA [15].

The data is tabulated in Table 4 and then the calculations with MEF equal to 2 are performed. DT is calculated using (3). MTC is calculated using (2). DLC and ALC are calculated using (10) and (9), respectively. OPC and OPF are calculated using (17) and (16), respectively. MSR, SAD, and SAC are calculated using (14) and (13), respectively. Afterwards, DTC for leased aircraft with subcharter option and no subcharter option are calculated with (19) and (20), respectively. Finally, the total maintenance cost (TMC) for subcharter and no subcharter option is calculated using (21) and (22), respectively.

In order to see how maintenance cost and downtime cost vary from one MRO to another, the same calculations are repeated for another three MROs with different MEF and LBR values. MEF varies from 1.8 to 2.1 and LBR varies
TABLE 4: Case study for MEF 2.

\begin{tabular}{|c|c|c|c|}
\hline Acronym & Seasonal & Winter & Summer \\
\hline $\mathrm{ACP}$ & No & 180 & 180 \\
\hline ALC & Yes & $\$ 175,000.00$ & $\$ 141,666.67$ \\
\hline $\mathrm{AOC}$ & Yes & $\$ 175,000.00$ & $\$ 141,666.67$ \\
\hline $\mathrm{BH}$ & Yes & 250 & 300 \\
\hline CIL & No & 315 & 315 \\
\hline CIM & No & $\$ 3,150$ & $\$ 3,150$ \\
\hline DLC & No & $\$ 8,333.33$ & $\$ 8,333.33$ \\
\hline DT & Yes & 21 & 17 \\
\hline DTCs & Yes & $\$ 560,000.00$ & $\$ 617,666.67$ \\
\hline DTCn & Yes & $\$ 255,287.20$ & $\$ 228,325.87$ \\
\hline EOL & No & 150 & 150 \\
\hline EOM & No & $\$ 7,500$ & $\$ 7,500$ \\
\hline LBR & Yes & $\$ 50.00$ & $\$ 40.00$ \\
\hline LF & Yes & $60 \%$ & $80 \%$ \\
\hline MEF & No & 2 & 2 \\
\hline MLC & Yes & 160 & 200 \\
\hline MLR & No & $\$ 250,000$ & $\$ 250,000$ \\
\hline MSR & Yes & $\$ 550,000$ & $\$ 840,000$ \\
\hline MTC & Yes & $\$ 251,212.50$ & $\$ 216,037.50$ \\
\hline MTL & No & 862.5 & 862.5 \\
\hline MTM & No & $\$ 43,125$ & $\$ 43,125$ \\
\hline NDM & No & 30 & 30 \\
\hline NFL & No & $100 \%$ & $100 \%$ \\
\hline NFM & No & $100 \%$ & $100 \%$ \\
\hline NPP & No & $\$ 7.08$ & $\$ 7.08$ \\
\hline NRL & No & 431.25 & 431.25 \\
\hline NRM & No & $\$ 21,563$ & $\$ 21,563$ \\
\hline OPC & Yes & $\$ 80,287$ & $\$ 86,659$ \\
\hline OPF & Yes & $\$ 765$ & $\$ 1,020$ \\
\hline SAC & Yes & $\$ 385,000$ & $\$ 476,000$ \\
\hline SAD & Yes & $\$ 18,333$ & $\$ 28,000$ \\
\hline SCR & Yes & $\$ 2,200$ & $\$ 2,800$ \\
\hline TMCs & Yes & $\$ 811,212.50$ & $\$ 833,704.17$ \\
\hline TMCn & Yes & $\$ 506,499.70$ & $\$ 444,363.37$ \\
\hline
\end{tabular}

from $\$ 60$ to $\$ 40$, respectively. As we have mentioned before, MEF value is lower for MRO with higher ranking in terms of delivery performance. As a consequence, the LBR value of the corresponding MRO will be high. The results of the calculation are tabulated in Table 5.

Taking into account the results given in Table 5, three important points are observed. The first one is that load factor (LF) and net profit per passenger (NPP) play important roles in determining the opportunity cost of the operator. In this case study, for opportunity cost calculation, NPP given by IATA [15] is a constant value at $\$ 7.08$ both throughout winter and summer. While in fact, as load factor varies according to the season, net profit value per passenger will vary as well. Hence, OPC is sensitive to the variation of NPP and LF. To observe TMCn variation in summer with different values of LF and NPP, a sensitivity analysis is carried out as shown in Table 6. 
TABle 5: Case study for different MRO.

\begin{tabular}{cccccc}
\hline Season & Variable & $\mathrm{MRO}_{1}$ & $\mathrm{MRO}_{2}$ & $\mathrm{MRO}_{3}$ & $\mathrm{MRO}_{4}$ \\
\hline \multirow{6}{*}{ Winter } & LBR & $\$ 60$ & $\$ 55$ & $\$ 50$ & $\$ 40$ \\
& MEF & 1.8 & 1.9 & 2 & 2.1 \\
& DT & 19 & 20 & 21 & 23 \\
& AOC & $\$ 158,333$ & $\$ 166,667$ & $\$ 175,000$ & $\$ 191,667$ \\
& SAC & $\$ 348,333$ & $\$ 366,667$ & $\$ 385,000$ & $\$ 421,667$ \\
& OPC & $\$ 72,641$ & $\$ 76,464$ & $\$ 80,287$ & $\$ 87,934$ \\
& DTCs & $\$ 506,667$ & $\$ 533,333$ & $\$ 560,000$ & $\$ 613,333$ \\
& DTCn & $\$ 230,974$ & $\$ 243,131$ & $\$ 255,287$ & $\$ 279,600$ \\
& MTC & $\$ 265,283$ & $\$ 259,127$ & $\$ 251,213$ & $\$ 223,073$ \\
& TMCs & $\$ 771,949$ & $\$ 792,460$ & $\$ 811,213$ & $\$ 836,406$ \\
& TMCn & $\$ 496,257$ & $\$ 502,258$ & $\$ 506,500$ & $\$ 502,673$ \\
\hline LBR & $\$ 55$ & $\$ 50$ & $\$ 45$ & $\$ 35$ \\
& MEF & 1.8 & 1.9 & 2 & 2.1 \\
& DT & 15 & 16 & 17 & 18 \\
& AOC & $\$ 125,000$ & $\$ 133,333$ & $\$ 141,667$ & $\$ 150,000$ \\
& SAC & $\$ 420,000$ & $\$ 448,000$ & $\$ 476,000$ & $\$ 504,000$ \\
Summer & OPC & $\$ 76,464$ & $\$ 81,562$ & $\$ 86,659$ & $\$ 91,757$ \\
& DTCs & $\$ 545,000$ & $\$ 581,333$ & $\$ 617,667$ & $\$ 654,000$ \\
DTCn & $\$ 201,464$ & $\$ 214,895$ & $\$ 228,326$ & $\$ 241,757$ \\
& MTC & $\$ 249,454$ & $\$ 242,419$ & $\$ 233,625$ & $\$ 204,606$ \\
& TMCs & $\$ 794,454$ & $\$ 823,752$ & $\$ 851,292$ & $\$ 858,606$ \\
TMCn & $\$ 450,918$ & $\$ 457,314$ & $\$ 461,951$ & $\$ 446,362$ \\
\hline
\end{tabular}

TABLE 6: Sensitivity analysis of TMCn in summer with different LF and NPP values.

\begin{tabular}{lcccc}
\hline \multicolumn{5}{c}{ Sensitivity analysis of TMCn } \\
$\$ 444,363$ & $\$ 8$ & $\$ 9$ & $\$ 10$ & $\$ 11$ \\
\hline $50 \%$ & $\$ 418,904$ & $\$ 426,554$ & $\$ 434,204$ & $\$ 441,854$ \\
$55 \%$ & $\$ 425,024$ & $\$ 433,439$ & $\$ 441,854$ & $\$ 450,269$ \\
$60 \%$ & $\$ 431,144$ & $\$ 440,324$ & $\$ 449,504$ & $\$ 458,684$ \\
$65 \%$ & $\$ 437,264$ & $\$ 447,209$ & $\$ 457,154$ & $\$ 467,099$ \\
$70 \%$ & $\$ 443,384$ & $\$ 454,094$ & $\$ 464,804$ & $\$ 475,514$ \\
$75 \%$ & $\$ 449,504$ & $\$ 460,979$ & $\$ 472,454$ & $\$ 483,929$ \\
$80 \%$ & $\$ 455,624$ & $\$ 467,864$ & $\$ 480,104$ & $\$ 492,344$ \\
$85 \%$ & $\$ 461,744$ & $\$ 474,749$ & $\$ 487,754$ & $\$ 500,759$ \\
$90 \%$ & $\$ 467,864$ & $\$ 481,634$ & $\$ 495,404$ & $\$ 509,174$ \\
$95 \%$ & $\$ 473,984$ & $\$ 488,519$ & $\$ 503,054$ & $\$ 517,589$ \\
$100 \%$ & $\$ 480,104$ & $\$ 495,404$ & $\$ 510,704$ & $\$ 526,004$ \\
\hline
\end{tabular}

Secondly, as MEF decreases, MTC increases. This is because low MEF value corresponds directly to high LBR. For that reason, $\mathrm{MRO}_{4}$, which has the highest MEF and the lowest LBR value, gives the lowest MTC both in winter and summer. Unfortunately, this does not mean that $\mathrm{MRO}_{4}$ yields the lowest downtime cost (DTC) at the same time. From the table, we can see that in reverse, as MEF increases, this time DTC increases. Hence, $\mathrm{MRO}_{1}$ with the lowest MEF and highest LBR value gives the lowest downtime cost for winter and summer. This is due to the fact that higher MEF means higher performance delivery, which corresponds directly to lower turn-around time or downtime (DT). Nonetheless, the analysis could not stop only in MTC and DTC calculations.
The total maintenance cost (TMC) will be calculated. Interestingly, the result is that $\mathrm{MRO}_{1}$ yields the lowest TMC in winter both for subcharter $(\$ 771,949)$ and no subcharter $(\$ 496,257)$ option. In summer, the lowest TMC for subcharter $(\$ 794,454)$ and no subcharter $(\$ 446,362)$ option is provided by $\mathrm{MRO}_{1}$ and $\mathrm{MRO}_{4}$, respectively.

Thirdly, subcharter and no subcharter option types of DTC and TMC are examined. As we have discussed before, no subcharter option means that operator would prefer to bear opportunity cost than subcharter cost. In this case, from Table 4 we can see that DTC and TMC for subcharter option are much higher compared to no subcharter option. This may be related to the NPP and LF that we have chosen during opportunity cost calculation. Nevertheless, from the sensitivity analysis tabulated in Table 6 , it can be seen that even when the operator has $100 \%$ load factor with net profit per passenger of $\$ 11$, no subcharter option $(\$ 526,004)$ is still much more economic than subcharter option $(\$ 833,704)$. Assuming that these values are acceptable, this case study shows that subchartering during maintenance is not feasible. However, for a scheduled operator, which already has their flights scheduled and published in advance, sometimes cancelling a flight would not be possible and therefore subchartering is unavoidable. On top of that, from the table, it can be deduced that subchartering during summer $(\$ 833,704.17)$ is more expensive than in winter $(\$ 811,212.50)$.

As a conclusion, by comparing the total maintenance cost of four different MRO in winter and summer for subcharter and no subcharter option, no subcharter option yields the lowest total maintenance cost both throughout winter and summer. During winter, it is $\mathrm{MRO}_{1}$ with low MEF and high LBR value, which shows the lowest cost with $\$ 496,257$. While in summer, $\mathrm{MRO}_{4}$ with high MEF and low LBR shows the lowest cost with $\$ 446,362$. Thus, this case study provides the evidence that, in many cases, the cheapest maintenance pricing is not the most economical solution and the traditional maintenance scheduling practices do not yield the best overall cost performance. In this respect, this study validates the new method to investigate further the new aspects of maintenance scheduling.

\section{Conclusion}

At the first stage, this study discussed the maintenance cost that the operator has to bear during maintenance. The maintenance cost elements of aircraft's scheduled checks have been described. Although some of these elements have deterministic characteristic, nonroutine elements contain probabilistic characteristics, which are affected by the variation of aircraft type, age, and operation. TAT term for scheduled maintenance is defined, which is later referred to as DT (downtime) in cost calculation. Besides the existence of direct maintenance cost, which includes the costs of maintenance crews, equipment, and materials, there is another inevitable cost, namely, downtime cost. There are few papers referring to downtime as a cost driver during scheduled maintenance and even in some of those downtime cost is neglected claiming that downtime is a natural fact of maintenance; therefore it is not considered as a part of the analytical decision making 
process. As our main argument, we introduce downtime cost with its monetary value and add its seasonal characteristic, which is still a virtual parameter. To model the accurate downtime cost is not straightforward, but it can be measured at each case by taking into account all associated costs of delayed or cancelled flights to an operator. In that case, the main objective of this study is to develop a new model and analysis technique on downtime cost calculation.

Our model's structure is based on a deeper insight on actual data coming from a MRO and a startup airline. Because of confidentiality reasons, the corresponding data are presented with normalization. Other papers on this topic such as $[11,12]$ also do not actually present any model data for validation. We are unfortunately limited by this inherent nature of MRO and airline business. However, in our paper, we provided some insight on the model's validity by utilizing Figures 1 and 3. Figure 1 shows average monthly revenue, which includes seasonal characteristics of a startup operator based in Istanbul, Turkey. The graph contains real business data of the corresponding airline. Furthermore, Figure 3 gives average monthly revenue from base maintenance of a MRO based in Istanbul, Turkey. However, due to confidentiality reasons, in both graphs, normalization is utilized.

Downtime cost models for scheduled operators and ACMI operators have been developed. Each model consists of aircraft ownership cost and either subcharter cost or opportunity cost. These models give simple expressions for two different possible scenarios. The first scenario is that, during downtime, operators may choose to use subcharter service and pay for subcharter cost. While in the second scenario, instead of paying for subcharter cost, they may choose to bear the opportunity cost. This means losing the profit that they might be able to gain if they would fly during downtime. By using and understanding the actual data coming from MRO and airline, our model is inherently compliant with the business nature. In addition to that, a case study in which actual numbers coming from a MRO, an airline and IATA is given.

Performing downtime cost calculation for different maintenance period is necessary. This calculation will assist operators to have better bargaining position with MRO organizations in terms of maintenance prices and rates. By comparing the total cost for various scenarios, operators will be able to decide not only which scenario suits them the best but also which scenario has the lowest total cost. This model will help operators not only to determine the best time to schedule maintenance but also to reduce the total maintenance cost and accordingly, the aircraft's total operating cost.

\section{Future Work}

This study is the beginning of the detailed analysis of downtime cost calculation during maintenance scheduling. Two models, one for subcharter option and the other one for no subcharter option, are introduced. However, these models need to be improved further to be able to catch the uncertain characteristics, not only due to nonroutine originated maintenance costs but also due to variation in aircraft's demand according to the season and geographical region. These uncertainties will affect not only subcharter cost and opportunity cost, but also the maintenance cost offered by MRO. One such improvement can be done by using stochastic modeling of the overall maintenance cost including downtime and nonroutine elements of the maintenance cost.

\section{Abbreviation}

ACP: Aircraft capacity

ALC: Aircraft lease cost during downtime

AOC: Aircraft ownership cost

BH: Block hour per month

C: $\quad$ Index for chartered flight

CIL: Cosmetic items labor

CIM: Cosmetic items material

CMV: Current market value

DLC: Daily lease cost

DT: Downtime number of days

DTC: Downtime cost

DTCs: Downtime cost with subcharter option

DTCn: Downtime cost with no subcharter option

EOL: Engineering order labor

EOM: Engineering order material

LBR: Labor rate

LF: Load factor

MEF: $\quad$ MRO efficiency factor

MLC: MRO labor capacity

MLR: Monthly lease rate

MOC: Monthly ownership cost

MSR: Monthly subcharter rate

MTC: Maintenance cost

MTL: MPD tasks labor

MTM: MPD tasks material

NDM: Number of days in one month

NFL: Nonroutine labor factor

NFM: Nonroutine material factor

NPP: Net profit per passenger

NRL: Nonroutine labor

NRM: Nonroutine material

OPC: Total opportunity cost

OPCc: Total opportunity cost for ACMI operator

OPCs: Total opportunity cost for scheduled operator

OPF: Opportunity cost per flight

OWC: Ownership cost during downtime

OWD: Daily ownership cost

$S: \quad$ Index for scheduled flight

SAC: Subcharter cost during downtime

SAD: Daily subcharter cost

SCR: Subcharter rate

TAT: Turn-around time

TMCs: Total maintenance cost with subcharter option

TMCn: Total maintenance cost with no subcharter option.

\section{Conflict of Interests}

The authors declare that there is no conflict of interests regarding the publication of this paper. 


\section{References}

[1] P. Gupta, M. Bazargan, and R. N. McGrath, "Simulation model for aircraft line maintenance planning," in Proceedings of the Annual Reliability and Maintainability Symposium, pp. 387-391, Tampa, Fla, USA, 2003.

[2] M. Bazargan, "An optimization approach to aircraft dispatching strategy with maintenance cost: a case study," Journal of Air Transport Management, vol. 42, pp. 10-14, 2015.

[3] J. D. Hurst, "Operational availability modeling for risk and impact analysis," 1995, http://citeseerx.ist.psu.edu/viewdoc/download?doi=10.1.1.222.3546\&rep=rep1\&type $=$ pdf.

[4] Eurocontrol by University of Westminster, "Innovative cooperative actions of $\mathrm{R} \& \mathrm{D}$ in EUROCONTROL programme CARE INO III," Technical Discussion Document 9.0, 2008, https://www.eurocontrol.int/eec/gallery/content/public/documents/projects/CARE/CARE_INO_III/DCI_TDD9-0_Airline_ maintenance_marginal_delay_costs.pdf.

[5] C. Sriram and A. Haghani, "An optimization model for aircraft maintenance scheduling and re-assignment," Transportation Research Part A, vol. 37, no. 1, pp. 29-48, 2003.

[6] L. Clarke, E. Johnson, G. Nemhauser, and Z. Zhu, "The aircraft rotation problem," Annals of Operations Research, vol. 69, pp. 33-46, 1997.

[7] K. A. Muchiri and K. Smit, "Application of maintenance interval de-escalation in base maintenance planning optimization," Journal of Enterprise Risk Management, vol. 1, no. 2, pp. 63-75, 2009.

[8] IATA and MCTF, Airline Maintenance Cost Executive Commentary-An Exclusive Benchmark Analysis of Maintenance Cost Task Force (MCTF) FY 2013, IATA, 2014.

[9] N. Papakostas, P. Papachatzakis, V. Xanthakis, D. Mourtzis, and G. Chryssolouris, "An approach to operational aircraft maintenance planning," Decision Support Systems, vol. 48, no. 4, pp. 604-612, 2010.

[10] M. J. Dupuy, D. E. Wesely, and C. S. Jenkins, "Airline fleet maintenance: trade-off analysis of alternate aircraft maintenance approaches," in Proceedings of the IEEE Systems and Information Engineering Design Symposium (SIEDS '11), pp. 29-34, IEEE, Charlottesville, Va, USA, April 2011.

[11] U. D. Kumar, J. Crocker, J. Knezevic, and M. El-Haram, Reliability, Maintenance and Logistic Support: A Life Cycle Approach, Springer, 2000.

[12] H. Saranga, "Opportunistic maintenance using genetic algorithms," Journal of Quality in Maintenance Engineering, vol. 10, no. 1, pp. 66-74, 2004.

[13] Access Intelligence, "Lease rentals continue to sit on fence," Aircraft Value News, vol. 20, no. 16, pp. 3-4, 2011.

[14] A. Heiter, New Route Forecasting Process, Istanbul Technical University, Aviation Institute, Istanbul, Turkey, 2015, http://aviation .itu.edu.tr/img/aviation/datafiles/Lecture\%20Notes/NetworkFleetSchedule20142015/Lecture\%20Notes/Module\%2021\%20\%20New\%20Market\%20Forecasting\%20(April\% 202015).pdf.

[15] IATA Corporate Communications, "Airline profitability improves with falling oil prices," 2014, http://www.iata.org/pressroom/pr/Pages/2014-12-10-01.aspx.

[16] G. Gupta, Charter vs. scheduled airlines [Ph.D. dissertation], ProQuest, UMI Dissertations Publishing, 2008.

[17] D. Kim and C. Barnhart, "Flight schedule design for a charter airline," Computers and Operations Research, vol. 34, no. 6, pp. 1516-1531, 2007.
[18] Aircraft Commerce, "A320 family 1st \& 2nd base airframe check cost analysis," Issue no. 75, pp. 34, 39, 2011.

[19] Airbus, "A320 aircraft: A320 range, specifications (dimensions, seating capacity, performance, cabin)," http://www.airbus.com/ aircraftfamilies/passengeraircraft/a320family/a320/.

[20] P. Belobaba, A. R. Odoni, and C. Barnhart, The Global Airline Industry, John Wiley \& Sons, Chichester, UK, 2009. 


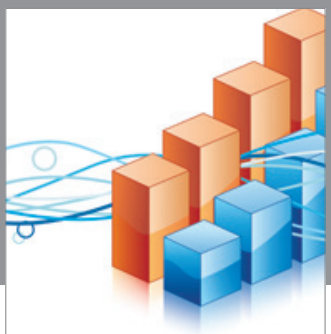

Advances in

Operations Research

vatem alat4

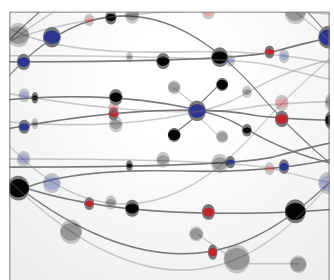

\section{The Scientific} World Journal
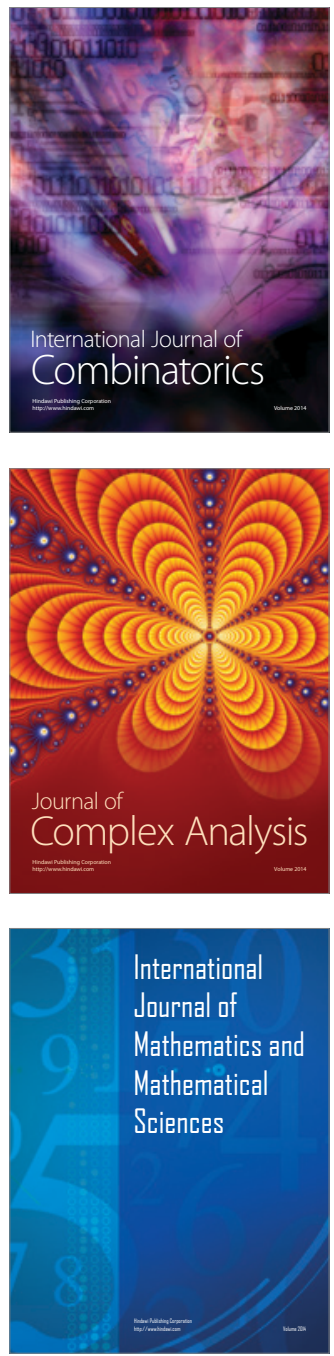
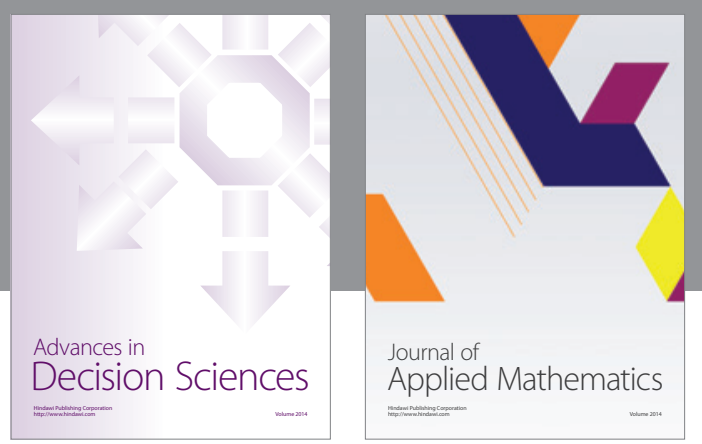

Algebra

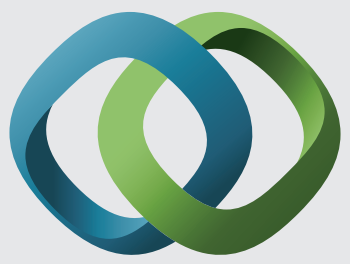

\section{Hindawi}

Submit your manuscripts at

http://www.hindawi.com
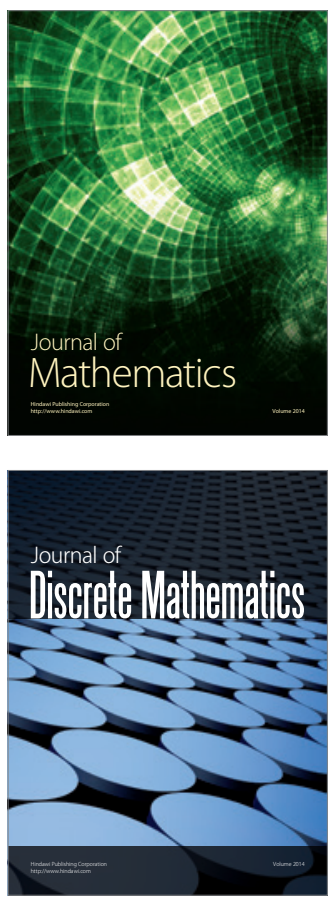

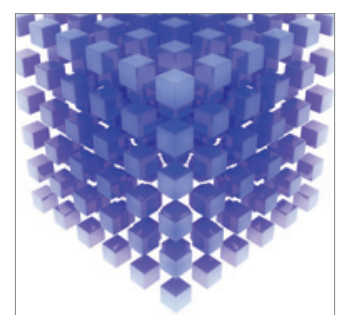

Mathematical Problems in Engineering
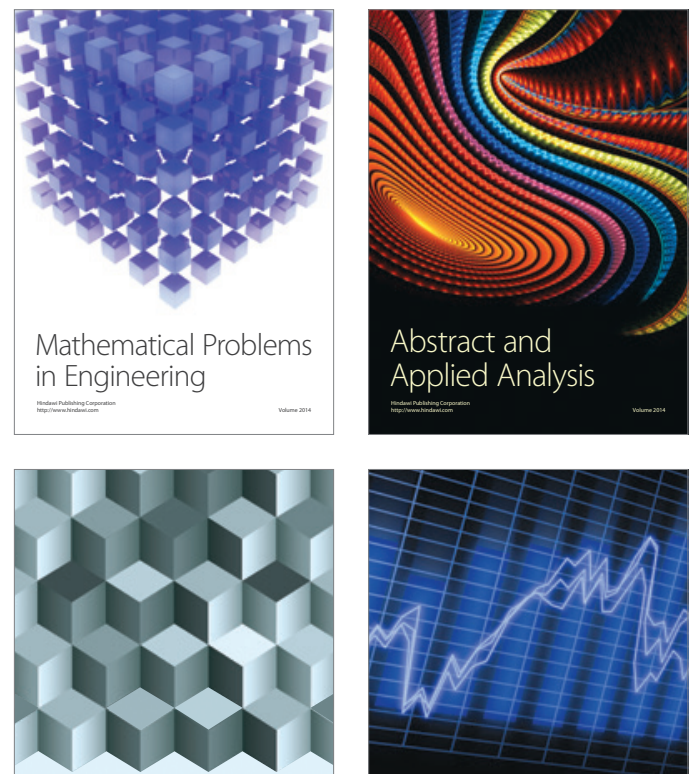

Journal of

Function Spaces

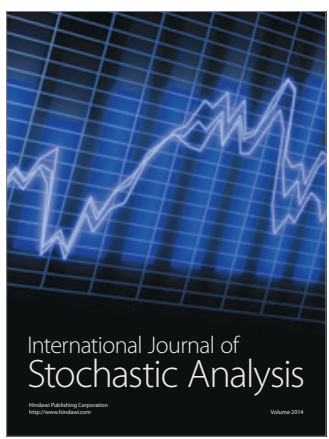

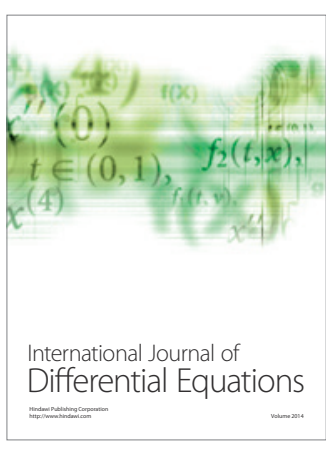
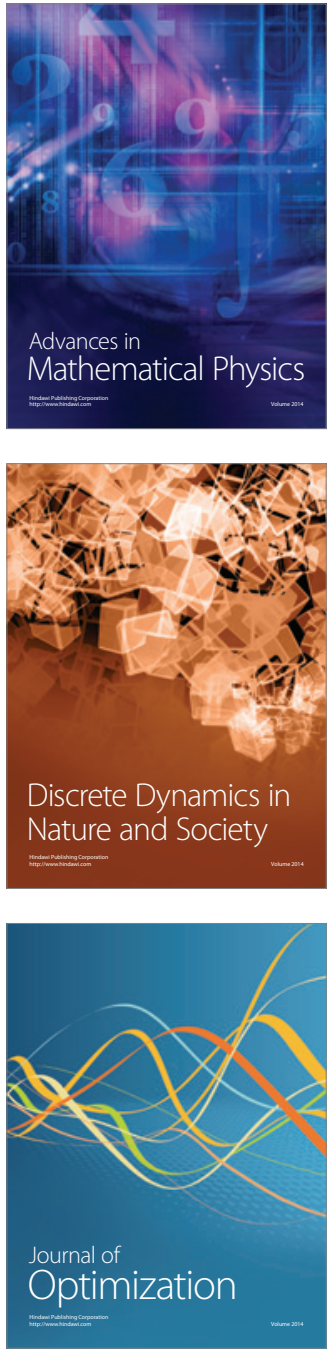